\title{
The Role of Knowledge and Attitude of Regular Students to Acceptance toward Special Educational Needs
}

\author{
Sheila Putri Fajrianti \\ Masters of Professional Educational Psychology \\ Atma Jaya Catholic University, Jakarta \\ sheila.201800040029@student.atmajaya.ac.id \\ Margaretha Purwanti \\ Mastersof Professional Educational Psychology \\ Atma Jaya Catholic University, Jakarta \\ marg.purwanti@atmajaya.ac.id
}

\begin{abstract}
These days, regular students' behaviours still reflect a low acceptance of students with special educational needs (SEN). Previous studies have revealed that the crucial factors to examine are regular students' knowledge about disabilities and attitudes. This study aims to determine the extent to which these two factors contribute to their acceptance of SEN. This quantitative research was conducted on 1248 participants from 14 public junior high schools in DKI Jakarta. Multiple linear regression analysis was run to determine peer acceptance from knowledge about disabilities and attitude. These variables statistically significantly contributed to peer acceptance, $F(2,1245)=612.95 \mathrm{I}, p<.05, R^{2}=.496$. Both variables added statistically significantly to peer acceptance, $p<.05$. While both knowledge and attitude matter in peer acceptance towards SEN, implications for practice should also involve developing an intervention program that not only focuses on knowledge only, but also targeting positive changes in attitudes.
\end{abstract}

Keywords: peer acceptance, special educational needs students, adolescent, public schools.

Received I0 February 202I/Accepted 9 June 202I @Author all rights reserved

\section{Introduction}

Since 20I4-20I5, local government of DKI Jakarta declared that public schools in DKI Jakarta should admit students with Special Educational Needs (SEN). This policy departs from a noble intention, that is to create child-friendly, inclusive education and to provide opportunities for SEN to develop academically and socially with their peers. Yet, only placing SEN in regular classes does not automatically enable them to develop academically and socially. There are many factors that influence the learning process of SEN in regular classrooms, from the teachers, parents, school facilitation, socio-economic status, to the mental health of SEN (Kamal, Asrar, Younes, \& Chishti, 20I4). 
For all students to develop and maximize their potential, the school and classrooms must be a conducive, peaceful, safe, and comfortable place to be at. Safety and comfort at school is a complex concept because it includes all factors that affect the physical and mental wellbeing of students in schools starting from the physical environment, psychologically, and socially. Students who feel insecure and uncomfortable at school tend to avoid school, so they skip school or miss their daily school activities (Jan \& Husain, 20I5). Insecurity and discomfort at school can also have a negative effect on student academic performance, mainly because they are more easily distracted, decreased concentration and difficulty focusing, and increased anxiety (Gittins, 20I4; Jan \& Husain, 20I5). Insecurity and discomfort at school predicts a decrease in student involvement in learning, as well as a decrease in student reading achievement and mathematics achievement (Ripski \& Gregory, 2009). In contrast, students who reported feeling safe and comfortable in school were more engaged and able to learn with focus and high attentiveness in the classroom (CôtéLussier \& Fitzpatrick, 2016).

One aspect that contributes to students' sense of security and comfort in school is the social aspect, which includes how they can relate to, interacts with, and are accepted by other individuals, especially their peers. Students in DKI Jakarta spend \pm 7-8 hours at school, 5 days a week. During that time, students will spend a lot of time with their classmates, both when studying in class and during recess or free times. Social acceptance of students by their peers is an important aspect in building their sense of security and comfort in school. This is emphasized by Schmidt, Dirk, and Schmiedek (2019) through their longitudinal research. Schmidt, Dirk, and Schmiedek (2019) found that students who were less well received by their peers tended to report more negative feelings, such as unhappiness, feeling lonely, and feeling afraid and uncomfortable while at school so they tend to avoid school activities. These negative feelings can ultimately have a negative effect on their academic achievement (Zarei, Heydari, Adli, 20 I I).

For some students, especially SEN, school is not necessarily the safest and most comfortable place to be. They are more prone to experiencing various forms of peer rejections, ranging from being bullied with harsh words, being ridiculed by inappropriate nicknames, being hurt physically, being laughed at in class when they were not able to 
answer questions from the teacher, being teased, being ignored, not being asked to talk to or join the game or conversation, avoided when having to do group assignments, so that they are labelled with certain characteristics (Saputi, 20I8).

This is not an ideal condition, especially for adolescent whom the main developmental tasks and needs are to explore and cultivate friendship (Santrock, 2014). Higher level of peer acceptance allows adolescents to form more healthy friendships, build higher self-esteem, reduce levels of anxiety and depression, and to develop their adaptability, empathy, and emotional regulation skills (Żurko, 20Il; Bukowski, Motzoi, \& Meyer, 2018). Peer acceptance can also have a positive impact on academic development and achievement in schools. Students who feel accepted, report higher learning motivation and academic achievement than students who are not well accepted by their peers (Zucchetti, Candela, Sacconi, \& Rabaglietti, 2015; Wentzel, 2017). The effect of peer acceptance on academic achievement becomes stronger if peers can provide support in learning, such as inviting to do assignments together, gather at group study, willing to teach, answer, or discuss questions together (Chen, 2005). These wide benefits of peer acceptance are not limited to regular students only but will also apply to SEN if they are to be in the right environment.

Several previous studies have tried to analyse what factors influence peer acceptance of SEN in public schools. De Boer, Pijl, Post, and Minnaert (2013) found that these factors can be categorized into 3 types, namely factors related to SEN itself (physical, socioeconomic, cognitive, etc.), factors related to regular students (gender, attitudes, knowledge), as well as factors related to the class or school (e.g.: availability of shadow/inclusive teachers, and classroom climate).

Generally, previous studies have found that one of the most significant factors in determining peer acceptance is a factor related to regular students themselves. The importance of factors related to regular students is not without reason. First, the factors associated with SEN itself tend to have very relative results, depending on SEN's age, age of peers, types and severity of their disabilities, whether SEN is receiving therapy or aids, as well as SEN's communication and socialization skills, and other factors that come from within SEN itself (De Boer, Pijl, Post, \& Minnaert, 20I3; Gökbulut, Gökbulut, \&Yeniasır, 
2017). Thus, the factors related to SEN are more likely to be intervened individually as the development of the SEN itself.

The teachers and school-related factors also influence how students interact and accept each other (Robinson, 2004; David \& Kuyini, 20I2). However, it is unlikely that teachers or other authority figures will always be role models in social interactions and always monitor the dynamics of social acceptance other than during class hours, especially in junior high school settings. In adolescence, the role of teachers and schools is still present, but tend to be gradually replaced by peer groups so that the effect is no longer as prominent as they were in younger age group.

Meanwhile, students themselves as a peer have the greatest impact on the dynamics of social acceptance among students, especially in the adolescent age group. This can happen because students spend the most time with friends for at least 7-8 hours each day in various activities ranging from studying in class, break time, to working groups at home. Thus, acceptance factors that are directly related to students, such as knowledge and attitudes, are important to be examined and intervened directly, especially in the context of adolescents.

In examining the factors related to regular students in the dynamics of acceptance towards SEN, one variable that is quite often and significantly discussed in the previous literature is attitude (Robinson, 2004; De Boer, Pijl, \& Minnaert, 20I2; De Boer \& Pijl, 20I6). In general, the attitudes of all stakeholders (parents of SEN, parents of regular students, teachers, other professionals in schools, and regular students themselves) are essential factors in the successful implementation of inclusive education (Schwab, 20I7). However, the attitude of regular students is a major concern in this study, related to their acceptance of SEN. De Boer and Pijl (2016) found that if regular students already held negative attitudes towards their friends with special needs, then their acceptance of these friends and other SENs in general will be lower. The attitudes of regular students towards SEN still tend to have neutral to negative nuances, and this negative attitude has the potential to prevent SEN from gaining opportunities for social interaction in the classroom and school environment (De Boer, Pijl, Minnaert, 20I2). Attitudes themselves can be developed and changed from a 
variety of factors and dynamics - from gender, age, parenting styles and attitudes of parents, socio-economic conditions, life satisfaction, types of special needs that SEN has, to the knowledge that regular students have about disabilities. (De Boer, Pijl, \& Minnaert, 20I2; Vignes, et all, 2009; Campbell \& Barger, 2014).

Another variable that is also widely researched in knowing the dynamics of regular student acceptance towards SEN is knowledge. In general, the research found that the more knowledge students have about special needs (including what special needs are, what are the characteristics of their friends with special needs, and what they can do to help SEN), the more positive their attitude and acceptance will be (De Boer, Pijl, \& Minnaert, 20I2; Campbell \& Barger, 20I4). By having knowledge about disabilities, individuals understand the causes behind the behavior of individuals with special needs which may be considered unnatural or inappropriate. In the end, sufficient knowledge will be able to reduce negative judgment and discriminatory behavior (Sasson \& Morrison, 2019), also increasing positive behavioral intentions (Mavropoulou \& Sideridis, 20I4). Providing an understanding of the characteristics and ways of helping SEN can make regular students more willing and more capable in helping their SEN peers socially and academically (Okilwa \& Shelby, 20I0). Previous studies had established the relationships and dynamics between either knowledge and peer acceptance, or attitude and peer acceptance only. This study aims to dive deeper and understand these three most significant and interrelated variables in social dynamics of acceptance and friendship for SENs. This study also serves the purpose of preliminary information to create a ready-to-use, relevant, and appropriate intervention to increase peer acceptance towards SENs, specifically in adolescent ages students.

\section{Method}

Participants

Due to local government's policy, all public schools in DKI Jakarta should technically have SEN in their school. In fact, not all did. Mainly either because the SEN students were transferred to another school, has just graduated, or coincidentally no SEN students applied this year. A careful control procedure then applied, having the public schools screened through online local government's database and personal contacts. A total of I4 
public junior high schools in DKI Jakarta were part of this study, resulting in a total sample of 1248 regular students $\left(63.8 \%\right.$ female). The students attended grades 8 to $9\left(M_{\text {age }}=14.3\right.$, $\mathrm{SD}=0.8)$.

\section{Procedure}

The corresponding schools were given informed consent, containing the concise background and aims of this study, and stating that they give consent for the students to participate in filling the given questionnaires. The informed consents were signed by officials of the schools. The students were also given informed consent directly at the beginning of the questionnaire.

In this study, the 7th grade students were excluded because they had no experience in direct contact with their SEN peer, while the 8th or 9th graders had the experience of direct, face-to-face interaction with SEN before. To ensure that the participants collected were the right ones to answer research questions, researcher formulated inclusion criteria as follows:

a. A student at public junior high school in DKI Jakarta,

b. Registered as a regular student, meaning she/he did not have any kind of disability that qualifies her/him as a SEN,

c. Currently on grade 8 or 9 , and

d. Learning on the same class with at least one (I) SEN.

Because this study was conducted in December 2020 through February 202I, all the students were still instructed to Learn from Home (Belajar dari Rumah) due to COVID-19 pandemic. Therefore, all the data collected online via Google Forms. The Google Forms links were sent to the students by their homeroom teachers or guidance counseling teachers.

\section{Measures}

All the measures used in this study had been tested for validity and reliability during a trial test period earlier, involving a total sample of $I 2 I$ regular students (6I.2\% female) from 2 public junior high school in DKI Jakarta, attended grades 8 to $9\left(M_{\text {age }}=14.2, S D=0.7\right)$. 
Demographic. All participants were asked to state their name, gender (female or male), age (in years), their school, and their grade (8 or 9).

Knowledge. Regular students' knowledge about disability was measured using a tailored questionnaire about disability for the context of this study. The researcher conceptualized and operationalized the items accordingly to the categories from Hunt and Hunt (2004): basic information about disability, awareness, barriers, myth and misperceptions, impact, and etiquette. Participants were instructed to read the statements and decide if the statement is true or false. Each correct answer gained one (I) point, where every wrong answer was given zero (0) point. Higher score on this knowledge questionnaire indicates a higher knowledge about disability. Through a thorough process of item selections, it is found that fourteen (14) items are valid, has good discriminant power, and good internal consistency reliability $(\alpha=0.78 \mathrm{I})$.

Attitude. Regular students' attitude towards their SEN peers was measured using ChedokeMcMaster Attitudes Toward Children with Handicaps (CATCH) by Rosenbaum, Armstrong, and King (1986). Participants were instructed to read the statements and indicate their level of agreement on a 4-point Likert scale, I (totally disagree) to 4 (totally agree). Higher $\mathrm{CATCH}$ score indicating more positive attitude. Originally consisting of thirty-six (36) items, trial test shows that seven (7) of the items were invalid. All the invalid items were excluded; therefore twenty-nine (29) items were used for this study. The trial period shows that the twenty-nine items $\mathrm{CATCH}$ has strong internal consistency reliability $(\alpha=0.909)$.

Peer Acceptance. In this study, peer acceptance was measured using Peer Acceptance Scale (PAS) by Piercy, Wilton, and Townsend (2002). Originally consisting only five (5) items, researchers added sixteen more items to depict the wide range of behaviors associated with peer acceptance especially in the context of adolescent with more accuracy. PAS provided three (3) answer choices ranging from "Yes, I would", "Maybe", and "No, I would not". The higher the score on PAS reflected a higher acceptance towards SEN peers. After 
the trial period, it is proven that all twenty-one $(2 \mathrm{l})$ items were valid and that this measure has strong internal consistency reliability $(\alpha=0.935)$.

\section{Data Analyses}

To answer the research questions, a multiple linear regression analysis was conducted. To ensure that the regression model is proper, several classical assumptions tests were run. The classical assumptions test showed that the regression model has a linear relationship, no multicollinearity, no heteroskedasticity, no autocorrelation, and that the residuals were distributed normally. Therefore, this multiple linear regression model is proper.

\section{Result}

The objectives of this study are to investigate the contributions of knowledge about disability to peer acceptance towards SEN, contributions of attitude to peer acceptance towards SEN, and both variables simultaneously to peer acceptance towards SEN. Prior to that, this study will first disseminate the descriptive findings about these three (3) variables.

Table I

Descriptive results

\begin{tabular}{lccc}
\hline & High/Positive & Moderate/Neutral & Low/Negative \\
\hline Knowledge & $30.9 \%$ & $54.9 \%$ & $14.2 \%$ \\
Attitude & $18 \%$ & $68.5 \%$ & $13.5 \%$ \\
Acceptance & $27.4 \%$ & $55.6 \%$ & $17 \%$ \\
\hline
\end{tabular}

As shown on the descriptive results (Table I) above, most of the participants (54.9\%) had moderate amount of knowledge about disability. Even though considerable number of participants (30.9\%) who already had high amount of knowledge about disability, there are also participants who have knowledge about disabilities in the low category (14.2\%). Most of the participants (55.6\%) also had neutral attitude towards their SEN peer, while the number of positive (18\%) and negative (13.5\%) attitude were relatively closely tied. Majority of the participants $(55.6 \%)$ had moderately accepted their SEN peer. Although there are 
participants who had high rate of acceptance (27.4\%), there are also sizeable number of participants who had low acceptance towards their SEN peer (17\%).

The result of multiple linear regression analysis can be examined on Table II below. Information included on the table were the standardized $\beta$ value, the significancy value, the coefficient of determination $\left(R^{2}\right)$, and the ANOVA result $(F)$.

Table 2

Multiple linear regression analysis

\begin{tabular}{lllrlllll}
\hline & \multicolumn{2}{c}{$\begin{array}{l}\text { Unstandardized } \\
\text { coefficients }\end{array}$} & $\begin{array}{c}\text { Standardized } \\
\text { coefficients }\end{array}$ & & & & \\
\cline { 2 - 5 } Predictor & $\mathrm{B}$ & $\mathrm{SE}$ & $\mathrm{B}$ & $\mathrm{t}$ & $\mathrm{R}^{2}$ & $\mathrm{~F}$ & $\mathrm{P}$ \\
\hline Knowledge & .139 & .059 & $.05 \mathrm{I}$ & 2.367 & & & .018 \\
Attitude & .583 & .018 & .685 & 2.903 & .496 & $612.95 \mathrm{I}$ & .000 \\
\hline
\end{tabular}

Note. ${ }^{*} \mathrm{p}<0.05$

Referring to the table II above, it can be inferred that $\mathrm{HO}^{\prime}$ is rejected. Thus, there is a contribution from knowledge about disabilities to regular students' acceptance towards SEN in public junior high schools in DKI Jakarta $(\beta=0.05 \mathrm{I}, \mathrm{p}<0.05)$. It can also be concluded that $\mathrm{HO}^{2}$ is rejected, because there is a contribution from attitude to the acceptance of regular students to SEN in public junior high schools in DKI Jakarta $(\beta=$ 0.685, $\mathrm{p}<0.05)$.

From the $\mathrm{F}$ value at the table II above, it can be concluded that $\mathrm{H}^{3}$ is also rejected. Both variables contributed simultaneously to acceptance towards SEN in public junior high schools in DKI Jakarta $(F=612.95 \mathrm{I}, \mathrm{P}<0.05)$. Simultaneously, both variables contributed to approximately $49.6 \%$ of regular students' acceptance towards SEN.

\section{Discussion}

Knowledge is indeed fundamental and vital in social acceptance, especially when we are talking about certain things or groups that often have a bad stigma. Without basic 
knowledge about disabilities, the public can be trapped in negative prejudice, stereotyping, labeling, and discrimination against individuals with special needs (Aronson, Wilson, \& Akert, 2015). Yet, knowledge alone is not sufficient to change attitude and behavior especially for long-term outcome (Arlinghaus \& Johnston, 2017). How knowledge changes attitude and behavior is a rather complex, multidimensional process. Examining the amount, complexity, and relevance of the knowledge would be the plausible approach to grasp a better understanding of how knowledge shapes attitude and, eventually, behavior (Fabrigar, Petty, Smith, \& Crites, 2006).

Participants' amount and complexity of the knowledge might not be exactly complete. As the descriptive data on Table I previously indicated, some participants (I4.2\%) still have low amount of knowledge about disability. Moreover, a sizeable percentage of participants held a neutral (68.5\%) and negative (13.5\%) attitude towards SEN. Low knowledge and neutralnegative attitudes can be interpreted as confusion and scepticism about how to behave and act towards SEN. What the participants knows about disabilities could be a partial and/or inaccurate, especially when they were not given accessible information about disabilities. Most parents and schools did not brief or talk to students about this topic. As digital native generation, they are much more likely to dig information by themselves via Internet. Sadly, there is not much positive content about people with disabilities. On the contrary, online medias were still using improper terms about individuals with special needs, such as 'handicapped', 'sufferers', 'autism' in a less appropriate context, and overall framing individuals with special needs as a marginalized group (Apny \& Hasfi, 2019). Lack of relevant and accurate knowledge about disability from parents, family, school, or media can lead to inaccurate, incomplete beliefs about SEN.

Other than being incomplete and inaccurate, it is also possible that participants do not have any knowledge about the expected behaviors in the context of social acceptance. To be able to produce expected behaviors, it is crucial for individuals to have a clue about what to do (Fabrigar, Petty, Smith, \& Crites, 2006). Irrelevant, incomplete, or inaccurate knowledge can lead to unfamiliarity, anxiety, and eventually a more negative attitude (Fisher \&Purcal, 2016). For an example, students know not to call their SEN friends as "autistic", but they had no idea what the proper nomenclature is, so they chose to stay quiet and not engaging 
with the SEN. Thus, students are not expected to only has superficial pieces of information about disabilities, but also extended knowledge and skills on how to behave, act, help, and interact with their SEN friends daily.

Meanwhile, attitude contributes significantly to acceptance towards SEN. This result is consistent with previous research, that concluded that attitude and acceptance had a significant, positive correlation (De Boer, Pijl, Post, \& Minnaert, 20I3). Attitude became a significant factor, because attitude fundamentally shapes individuals' perception about their world around them, and then also shapes their behavior (Albarracín, Wang, Hong, \&Noguchi, 20II). In examining the dynamics of social relationship, acceptance and friendships are deeply influenced by affective component. This can be seen from the underlying components of friendship itself, which according to Campbell, Holderness, and Riggs (20I5), includes reciprocal candour, mutual interests, personableness, similarity, and physical attraction. These aspects suggest a rather emotional tone when it comes to forming acceptance and friendship. Attitudes can influence behaviors that have an affective element (Fabrigar, Petty, Smith, \& Crites, 2006), and in the context of this study, including peer acceptance. So, it was expected that attitudes were proven to have significantly contributed to peer acceptance of SEN.

Both variables contributed to acceptance for approximately $49.6 \%$, which according to Cohen's $\mathrm{R}^{2}$ interpretation guide, is indicating a large effect (Gravetter \& Wallnau, 20I3). Approximately $50.4 \%$ of regular students' acceptance towards SEN can be explained with other variables that are not included in this study, namely familial background, their personal characteristics, SEN's characteristics, and school-related factors. Previous researchers found that regular students' parents' attitude and knowledge about disability positively correlated with their children's' acceptance towards SEN at school (De Boer, Pijl, \& Minnaert, 2012). Also, students with previous exposure to individual with special needs (within the family or relatives) tend to have a better attitude towards individual with special needs (Hong, Kwon, \& Jeon, 2014). Vignes et al. (2009) also found out that students' quality of life correlates with their acceptance towards SEN. Demographic factors analysis such as gender, age, and class towards peer acceptance were inconclusive. 
We also must not forget that there is school and teacher environmental factors that still play a major role in the lives of students. Several studies have shown that as a role model for students, the knowledge and attitudes of teachers can mediate the acceptance of regular students towards SEN (Hughes, Zhang, Hill, 2006; David \& Kuyini, 20I2). On a macro scale, the classroom and school climate is also one of the predictors of acceptance towards SEN. A warm, positive, and cohesive classroom and school climate has been shown to increase engagement and acceptance among all school members, including SEN (Robinson, 2004; Kiuru, et all, 20I2).

\section{Conclusion}

This study aims to find out how knowledge about disabilities and attitudes contributes to the acceptance of regular students towards their SEN peers at the public junior high school in DKI Jakarta. Data collection was successfully carried out on a total of 1248 students from 14 schools via the Google Forms online questionnaire. Multiple regression model analysis was conducted in this study to determine the contribution of knowledge about disabilities and attitudes towards the acceptance of regular students to SEN. This regression model is a proper model because it has met the classical assumption test, namely that there is no autocorrelation, no heteroscedasticity, no multicollinearity, there is a linear relationship, and the residuals are normally distributed.

Through a series of statistical tests, it was showed that the variables of knowledge and attitudes simultaneously contributed significantly to the acceptance of regular students to SBK with the calculation of $F(2,1245)=612.951, P<0.05, R 2=0.496$. Both variables contribute significantly to peer's acceptance. However, it is shown that the attitude variable has a greater influence $(\beta=0.685, p<0.05)$ on acceptance than the knowledge itself $(\beta=$ $0.05 \mathrm{I}, \mathrm{P}<0.05)$. It can be inferred that to increase regular students' acceptance towards SEN, a complete, thorough approach is needed to simultaneously increase their knowledge and shapes their attitude to be more positive. 


\section{References}

Albarracín, D., Wang, W., Hong, L., \& Noguchi, K. (20I I). Structure of attitudes: Judgements, memory, and implications for change. In W. D. Crano, \& R. Prislin, Attitudes and attitude change (pp. 19-40). New York: Psychology Press.

Apny, N. A., \& Hasfi, N. (2019). Framing pemberitaanisu disabilitas dalam media online Suaramerdeka.com. Interaksi Online, 8(I), 99-I I0.

Arlinghaus, K. R., \& Johnston, C. A. (2017). Advocating for behavior change with education. Behavioral Medicine Review, I2(2), I I3-I I6. doi: I0.I I77/I5598276I7745479

Aronson, E., Wilson, T. D., \& Akert, R. M. (20I5). Social psychology (9th ed.). Boston: Pearson.

Bukowski, W. M., Motzoi, C., \& Meyer, F. (2018). Friendship as process, function, and outcome. In K. Rubin, W. M. Bukowski, \& B. Laursen, Handbook of peer interactions, relationships, and groups (pp. 217-23I). New York: The Guilford Press.

Campbell, J. M., \& Barger, B. D. (20/4). Peers' knowledge about and attitudes towards students with autism spectrum disorders. In V. B. Patel, V. R. Preedy, \& C. R. Martin, Comprehensive guide to autism (pp. 247-26I). New York: Springer.

Campbell, K., Holderness, N., \& Riggs, M. (20I5). Friendship chemistry: an examination of underlying factors. The Social Science Journal, 52(2), 239-247. doi:I0.10I6/j.soscij.20I5.0I.005

Chen, J. J.-L. (2005). Relation of academic support from parents, teachers, and peers to Hong Kong adolescents' academic achievement: The mediating role of academic engagement. Genetic, Social, and General Psychology Monographs, I 3 I (2), 77-I 27. doi:I0.3200/MONO.I3I.2.77-I 27

Côté-Lussier, C., \& Fitzpatrick, C. (2016). Feelings of safety at school, socioemotional functioning, and classroom engagement. Journal of Adolescent Health, 58(5), 543-550. doi:10.1016/j.jadohealth.2016.01.003

David, R., \& Kuyini, A. B. (20I2). Social inclusion: teachers as facilitators in peer acceptance of students with disabilities in regular classrooms in Tamil Nadu, India. International Journal of Special Education, 27(2), I57-168.

De Boer, A., \& Pijl, S. J. (20I6). The acceptance and rejection of peers with ADHD and ASD in general secondary education. The Journal of Educational Research, 109(3), 325-332. doi:10.1080/0022067I.2014.958812

De Boer, A., Pijl, S. J., Post, W., \& Minnaert, A. (20I3). Peer acceptance and friendships of students with disabilities in general education: the role of child, peer, and classoom variables. Social Development, 22(4), 83 I-844. doi:I0. I I I/j. I467-9507.20 I 2.00670.x

Fabrigar, L. R., Petty, R. E., Smith, S. M., \& Crites, S. L. (2006). Understanding knowledge effects on attitude-behavior consistency: the role of relevance, complexity, and amount of knowledge. Journal of Personality and Social Psychology, 556-577. doi:10.1037/0022-35|4.90.4.556 
Fisher, K. R., \&Purcal, C. (2016). Policies to change attitudes to people with disabilities. Scandinavian Journal of Disability Research, I-I4. doi:I0.1080/I50 I74 I9.20 I6.1222303

Gittins, D. (20I4). Impact of students' perception of safety on academic success. Pittsburgh: Duquesne University. Retrieved from https://dsc.duq.edu/etd/583

Gökbulut, Ö. D., Gökbulut, B., \&Yeniasır, M. (20I7). Social acceptance of students with special needs from peer viewpoint. EURASIA Journal of Mathematics, Science and Technology Education, I3(I I), 7287-7294. doi: I0.I2973/ejmste/79592

Gravetter, F. J., \&Wallnau, L. B. (20I3). Statistics for the behavioral sciences (9th ed.). Boston: Wadsworth Cengage Learning.

Hong, S.-Y., Kwon, K.-A., \& Jeon, H.-J. (20I4). Children's attitudes towards peers with disabilities: associations with personal and parental factors. Infant and Child Development, 23, 170-193. doi:10.1002/icd.1826

Hughes, J. N., Zhang, D., \& Hill, C. R. (2006). Peer assessments of normative and individual teacher-student support predict social acceptance and engagement among lowachieving children. Journal of School Psychology, 43(6), 447-463. doi:10.1016/j.jsp.2005.10.002

Hunt, C. S., \& Hunt, B. (2004). Changing attitudes toward people with disabilities: experimenting with an educational intervention. Journal of Managerial Issues, I6(2), 266-280.

Jan, M. A., \& Husain, S. (20I5). Bullying in elementary school: Its causes and effects on students. Journal of Education and Practice, 6(19), 43-57.

Kamal, S., Asrar, M., Younes, M., \& Chishti, A. F. (20I4). Factors affecting academic performance of special students: A case of Peshawar district. Social Science Research Network Electronic Journal, I-23. doi: 10.2139/ssrn.2755 I44

Kiuru, N., Poikkeus, A.-M., Lerkkanen, M.-K., Pakarinen, E., Siekkinen, M., Ahonen, T., \& Nurmi, J.-E. (20I2). Teacher-perceived supportive classroom climate protects against detrimental impact of reading disability risk on peer rejection. Learning and Instruction, 22, 331-339. doi:10.1016/j.learninstruc.2011.12.003

Mavropoulou, S., \&Sideridis, G. D. (20I4). Knowledge of autism and attitudes of children towards their partially integrated peers with autism spectrum disorders. Journal of Autism and Developmental Disorders, 44, I867-I885. doi:I0.1007/s I0803-0I4-2059-0

Okilwa, N. S., \& Shelby, L. (20I0). The effects of peer tutoring on academic performance of students with disabilities in grades 6 through 12: A synthesis of the literature. Remedial and Special Education, 3 I (6), 450-463. doi: I 0.I I77/074 I 93250935599 I

Piercy, M., Wilton, K., \& Townsend, M. (2002). Promoting the social acceptance of young children with moderate-severe intellectual disabilities using cooperative-learning techniques. American Journal of Mental Retardation, 107(5), 352-360. doi: I0.1352/0895-8017(2002) I07<0352:PTSAOY>2.0.CO;2

Ripski, M. B., \& Gregory, A. (2009). Unfair, unsafe, and unwelcome: Do high school students' perception of unfairness, hostility, and victimization in school predict 
engagement and achievement? Journal of School Violence, 8(4), 355-375. doi: $10.1080 / 15388220903 / 32755$

Robinson, M. J. (2004). Factors affecting peer acceptance of children with disabilities in regular schools. 2004: University of Tasmania.

Rosenbaum, P. L., Armstrong, R. W., \& King, S. M. (1986). Children's attitudes toward disabled peers: a self-report measure. Journal of Pediatric Psychology, I I (4), 5I 7-530. doi:10.1093/jpepsy/II.4.5I7

Santrock, J. W. (20I4). Adolescence (I5th ed.). New York: McGraw-Hill Education.

Saputi, V. (20I8). Penerimaan sekolah terhadap siswa berkebutuhan khusus (studi kasus di SMP Taman Dewasa Ibu Pawiyatan Yogyakarta). Jurnal Wida Orto didaktika, 7(6), 644-66I.

Sasson, N. J., \& Morrison, K. E. (2019). First impressions of adults with autism improve with diagnostic disclosure and increased autism knowledge of peers. Autism, 23(I), 50-59. doi: I0.1 I77//362361317729526

Schmidt, A., Dirk, J., \& Schmiedek, F. (2019). The importance of peer relatedness at school for affective well-being in children: Between- and within-person associations. Social Development, 28(4), 873-892. doi:10.1 I I I/sode. 12379

Schwab, S. (20I7). The impact of contact on students' attitudes towards peer with disabilities. Research in Developmental Disabilities, 62, 160-165. doi:10.1016/j.ridd.2017.01.015

Vignes, C., Godeau, E., Sentenac, M., Coley, N., Navarro, F., Grandjean, H., \& Arnaud, C. (2009). Determinants of students' attitudes towards peers with disabilities. Developmental Medicine \& Child Neurology, 5 I (6), 473-479. doi: I 0. I I I I/j. I 4698749.2009.03283.x

Wentzel, K. R. (20I7). Peer relationships, motivation, and academic performance at school. In J. Elliott, C. S. Dweck, \& D. S. Yeager, Handbook of competence and motivation: Theory and application (pp. 586-603). New York: The Guilford Press.

Zarei, E., Heydari, H., \& Adli, M. (20I3). The relationship between loneliness and social acceptance and the academic performance of students. Journal of Life Science and Biomedicine, 3(2), I7I-I75.

Zucchetti, G., Candela, F., Sacconi, B., \& Rabaglietti, E. (20I5). Friendship quality and school achievement: A longitudinal analysis during primary school. Journal of Applied School Psychology, 3I(4), 297-3I4. doi:I0.I080/I5377903.20I5.I084963

Żurko, M. (20I I). Friendship during adolescence: the necessity for qualitative research of close relationships. Polish Journal of Applied Psychology, 9(I), 2 I-38. 